\title{
Platelet derived growth factor and fibroblast growth factor basic levels in the vitreous of patients with vitreoretinal disorders
}

\author{
L Cassidy, P Barry, C Shaw, J Duffy, S Kennedy
}

\begin{abstract}
Aim-To determine the potential role of basic fibroblast growth factor (bFGF) and platelet derived growth factor (PDGF) in the pathogenesis of proliferative vitreoretinopathy (PVR).

Methods-An enzyme linked immunosorbent assay technique was used to determine the quantities of bFGF and PDGF in 38 vitreous samples taken from patients undergoing trans pars plana vitrectomy (PPV) for a variety of vitreoretinal disorders.

Results-bFGF levels ranged from undetectable to $318.7 \mathrm{pg} / \mathrm{ml}$. The mean concentration was $27.57 \mathrm{pg} / \mathrm{ml}$. PDGF levels ranged from undetectable to $160 \mathrm{pg} / \mathrm{ml}$, the mean concentration being $40.06 \mathrm{pg} / \mathrm{ml}$. Eight of 13 patients with clinical evidence of retinal detachment (RD) and PVR had significantly elevated bFGF concentrations, whereas only one of 11 patients with RD and no PVR had detectable bFGF; seven of eight patients with RD and PVR had elevated PDGF concentrations in the vitreous, whereas all 10 patients with $R D$ and no PVR had no detectable vitreous PDGF. Eight patients with vitreous haemorrhage had raised PDGF concentrations, and the levels were particularly high $(>120$ $\mathrm{pg} / \mathrm{ml}$ ) in those two patients with active neovascularisation. Two out of nine patients with vitreous haemorrhage had raised bFGF levels.

Conclusions-bFGF and PDGF concentrations are elevated in PVR even in the absence of vitreous haemorrhage, and not in patients with RD uncomplicated by PVR. This observation suggests that both cytokines may be involved in the pathogenesis of PVR.
\end{abstract}

(Br f Ophthalmol 1998;82:181-185)

Nuclear Medicine, $\mathbf{S t}$

Vincent's Hospital,

Dublin

M J Duffy

Correspondence to: Miss Lorraine Cassidy, Ophthalmology Department, Clarendon Wing, Leeds General Infirmary, Belmont Grove, Leeds LS2 9NS.

Accepted for publication 13 August 1997 detached retina and within the vitreous. These membranes are formed when a number of cell types including retinal pigment epithelial (RPE) cells, glial cells, macrophages, and fibroblasts migrate into the vitreous cavity, adhere to the retina and vitreous gel, proliferate, synthesise extracellular matrix, and eventually contract causing traction and reopening of breaks. ${ }^{1}$

RPE cells play a role in PVR. They have been demonstrated to produce platelet derived growth factor (PDGF)-like proteins, which account for a portion of mitogenic activity in $\mathrm{RPE}$ conditioned medium, ${ }^{3}$ and their proliferation is known to be triggered by PDGF. ${ }^{4}$

PDGF is a growth factor which is present together with platelet derived endothelial cell growth factor (PD-ECGF), transforming growth factor $\beta$ (TGF- $\beta$ ), and hepatocyte growth factor (HGF) in platelets. Experimental studies have shown that tractional retinal detachment can be induced in $72 \%$ of rabbit eyes within 3 weeks following intraocular injection of PDGF. ${ }^{5}$ It stimulates fibroblasts to synthesise and deposit collagen, ${ }^{6}$ and is the most important chemotactic and mitogenic agent for glia. ${ }^{7}$ PDGF also stimulates collagen gel contraction $^{9}$ and has been implicated in the pathogenesis of PVR. ${ }^{5} 81011$

It has been suggested that PDGF is an autocrine stimulator of growth in RPE which plays a role in retinal wound repair and epiretinal membrane formation, ${ }^{12}$ and may mediate the effects of transferrin, a protein present in large amounts in the vitreous, plasma, and in intraocular proliferative tissue, and a component which is essential for the growth of cultured cells. ${ }^{13}$

Basic fibroblast growth factor (bFGF) is a potent mitogen which stimulates cell proliferation and differentiation in many cell types and is implicated in the angiogenic response in wound healing. ${ }^{14}$ It has been isolated from a variety of sources including neural tissue, pituitary, adrenal cortex, corpus luteum, and placenta. ${ }^{15} 16$ It is an important angiogenic factor in bovine retina in experimental model systems. ${ }^{14}$

Elevated levels have been demonstrated in the vitreous of patients with proliferative diabetic retinopathy. ${ }^{17}$ bFGF has been shown to stimulate the proliferation of corneal endothelial cells in concentrations as low as 5 $\mathrm{pg} / \mathrm{ml}^{18}$ 
In this study we investigated the vitreous of patients with RD, RD + PVR, and vitreous haemorrhage for the presence of PDGF and bFGF in an attempt to determine if there was a correlation between vitreous levels and clinical grade of PVR, and the possible role of these cytokines in the pathogenesis of PVR. Control groups included vitreous aspirates from cadaver specimens and patients undergoing trans pars plana vitrectomy (PPV) for removal of intraocular foreign bodies.

\section{Materials and methods}

PATIENTS

Thirty eight patients were included in the study. The mean age was 48.7 years (range $10-80$ years). The male to female ratio was 1.5:1. The patients were divided into four groups according to the clinical diagnosis, which included RD with PVR ( $n=13), R D$ and no PVR $(n=11)$, vitreous haemorrhage $(n=9)$, and intraocular foreign body (IOFB) $(n=5)$. Three cadaveric specimens from individuals with no ocular disease were assayed for the presence of bFGF. Because PPV and gas tamponade without scleral buckling is the preferred management of primary rhegmatogenous retinal detachment in our unit, we were able to collect vitreous samples from patients with RD alone and patients with grade A PVR.

PVR was graded according to the classification recommended by the Retina Society Terminology Committee ${ }^{19}$ : grade A-vitreous haze and vitreous pigment clumps; grade B-wrinkling of the inner retinal surface, rolled edges of the retinal break, retinal stiffness, and vessel tortuosity; grade $\mathrm{C}$-full thickness retinal folds, C-1-involving 1 quadrant, C-2-2 quadrants, C-3-three quadrants; grade $\mathrm{D}$-fixed retinal folds in four quadrants, D-1 - wide funnel shape, D-2narrow funnel shape, D-3-closed funnel (optic nerve head not visible).

A diagnosis of grade A PVR was attributed to those patients with obvious pigment clumping within the vitreous cavity. Individuals who were classified as having RD and no PVR had been carefully examined and found to have no visible pigment clumping within the vitreous cavity.

SPECIMENS

Vitreous aspirates were obtained from 38 patients undergoing PPV using the standard three port vitrectomy technique. A $5 \mathrm{ml}$ syringe connected to the ocutome was used to aspirate $0.5-1 \mathrm{ml}$ of undiluted vitreous. Vitreous samples from the cadaver eyes were obtained within 6 hours of demise using an 18 gauge needle and syringe. All specimens were immediately labelled and stored in a liquid nitrogen container at $-20^{\circ} \mathrm{C}$ until the assay was performed.

ASSAY

Commercially available immunoassay kits (Quantikine UK) were used to quantitate levels of human PDGF and bFGF levels in the vitreous samples obtained.
Table 1 No of patients with detectable vitreous PDGF concentrations $(n=31)$

\begin{tabular}{llc}
\hline Vitreoretinal pathology & Detectable & Undetectable \\
${ }^{\star} \mathrm{RD}+\mathrm{PVR}$ & 7 (mean $55.1 \mathrm{pg} / \mathrm{ml})$ & 1 \\
${ }^{\star} \mathrm{RD}$ & 0 & 10 \\
Vitreous haemorrhage & 8 (mean $73.3 \mathrm{pg} / \mathrm{ml})$ & 0 \\
IOFB & 4 (mean $29 \mathrm{pg} / \mathrm{ml})$ & 1
\end{tabular}

$\mathrm{RD}=$ retinal detachment PVR $=$ proliferative vitreoretinopathy.

^Statistical analysis using the Wilcoxon rank sum test indicates that PDGF concentrations are significantly higher in patients with RD and PVR than in patients with RD alone at the $\alpha<$ 0.001 significance level.

PDGF and bFGF immunoassays are solid phase enzyme linked immunosorbent assays (ELISA) which measure the cytokine levels in less than 4.5 hours.

Both assays employ the quantitative "sandwich" ELISA technique. Monoclonal antibodies specific for the relevant cytokine-that is, bFGF (the PDGF assay recognises both the A and $\mathrm{B}$ chain components of PDGF), are coated onto the microtitre plate provided in the kit. Standards and samples are pipetted into the wells in duplicate and any bFGF present is bound by the immobilised antibodies.

After washing away any unbound proteins, an enzyme linked polyclonal antibody specific for bFGF is added to the wells and colour develops in proportion to the amount of bFGF bound in the initial step. The colour development is arrested and the intensity of the colour is measured using a spectrophotometer. The duplicate readings are averaged. The optical density is then plotted against the bFGF concentrations in the standard wells, and by comparing the optical density of the samples to this standard curve, the concentration of the bFGF in the unknown samples is determined.

PDGF levels were determined in 31 samples, while bFGF levels were determined in 38 samples, and in three cadaveric samples in which no ocular pathology was present.

\section{STATISTICS}

Comparisons between the difference in vitreous PDGF levels in samples with $\mathrm{RD}$ alone and those with RD complicated by PVR were analysed using the Wilcoxon rank sum test. The same was done for bFGF.

\section{Results}

PDGF concentrations in the vitreous of 31 patients ranged from undetectable (in 13 samples) to $160 \mathrm{pg} / \mathrm{ml}$. All 19 vitreous samples with detectable PDGF had concentrations ranging between 6 and $160 \mathrm{pg} / \mathrm{ml}$ (mean 40.06 $\mathrm{pg} / \mathrm{ml}$ ).

The number of patients divided according to their vitreoretinal condition with detectable PDGF concentrations are summarised in Table 1; these included seven patients with retinal detachment complicated by PVR, eight patients with vitreous haemorrhage, and four with IOFB.

In all, $87.5 \%(7 / 8)$ of those patients with $\mathrm{RD}$ + PVR had detectable vitreous PDGF concentrations (mean $55 \mathrm{pg} / \mathrm{ml}$; range 6-105 pg/ml). 
Table 2 PDGF and bFGF concentrations

\begin{tabular}{|c|c|c|c|}
\hline \multirow[b]{2}{*}{ Patient no } & \multirow[b]{2}{*}{ Retinal pathology } & \multicolumn{2}{|c|}{ Cytokine concentration ( $\mathrm{pg} / \mathrm{ml}$ ) } \\
\hline & & $P D G F$ & $b F G F$ \\
\hline 1 & RD + PVR grade A & 105 & undetectable \\
\hline 2 & $\mathrm{RD}+$ PVR grade C-3 & 6 & 22 \\
\hline 3 & RD + PVR grade A & 65 & 36 \\
\hline 4 & RD + PVR grade A & 60 & 50 \\
\hline 5 & $R D+$ PVR grade $A$ & 80 & undetectable \\
\hline 6 & RD + PVR grade C-2 & undetecta ble & undetectable \\
\hline 7 & $\mathrm{RD}+\mathrm{PVR}$ grade C-2 & 60 & undetectable \\
\hline 8 & RD + PVR grade A & 65 & 80 \\
\hline 9 & RD + PVR grade C-3 & not done 318.7 & \\
\hline 10 & RD + PVR grade B & not done 212.6 & \\
\hline 11 & RD + PVR grade $B$ & not done 199.5 & \\
\hline 12 & $\mathrm{RD}+\mathrm{PVR}$ grade C-1 & not done 118.9 & \\
\hline 13 & RD + PVR grade B & not done & undetectable \\
\hline 14 & $\mathrm{RD}$ & undetectable & undetectable \\
\hline 15 & $\mathrm{RD}$ & undetectable & undetectable \\
\hline 16 & $\mathrm{RD}$ & undetectable & undetectable \\
\hline 17 & $\mathrm{RD}$ & undetectable & 7 \\
\hline 18 & $\mathrm{RD}$ & undetectable & undetectable \\
\hline 19 & $\mathrm{RD}$ & undetectable & undetectable \\
\hline 20 & $\mathrm{RD}$ & undetectable & undetectable \\
\hline 21 & $\mathrm{RD}$ & undetectable & undetectable \\
\hline 22 & $\mathrm{RD}$ & undetectable & undetectable \\
\hline 23 & $\mathrm{RD}$ & undetectable & undetectable \\
\hline 24 & $\mathrm{RD}$ & not done & undetectable \\
\hline 25 & IOFB & 40 & undetectable \\
\hline 26 & IOFB & 30 & undetectable \\
\hline 27 & IOFB & 40 & undetectable \\
\hline 28 & IOFB & 35 & undetectable \\
\hline 29 & IOFB & undetectable & 19 \\
\hline 30 & VH/NVD/BRVO & 160 & undetectable \\
\hline 31 & VH/HST & 40 & 5 \\
\hline 32 & $\mathrm{VH} /$ perforation & 125 & undetectable \\
\hline 33 & VH/HST & 36 & undetectable \\
\hline 34 & $\mathrm{VH} / \mathrm{HST}$ & 35 & undetectable \\
\hline 35 & VH/HST & 40 & 9 \\
\hline 36 & VH/HST & 60 & undetectable \\
\hline 37 & VH/PDR/NVD & 120 & undetectable \\
\hline 38 & VH/NVE/BRVO & not done & undetectable \\
\hline
\end{tabular}

$\mathrm{RD}=$ retinal detachment; $\mathrm{PVR}=$ proliferative vitreoretinopathy; IOFB = intraocular foreign body; $\mathrm{VH}=$ vitreous haemorrhage; $\mathrm{NVD}=$ neovascularisation of the disc; $\mathrm{BRVO}=$ branch retinal vein occlusion; $\mathrm{HST}=$ horseshoe tear; $\mathrm{NVE}=$ neovascularisation elsewhere.

No patient with RD uncomplicated by PVR had detectable concentrations of PDGF (see Table 3). The difference between these two groups was statistically significant with a confidence level of 0.001 when analysed with the Wilcoxon rank sum test. Patients with lower grades of PVR tended to have higher vitreous concentrations of PDGF (Table 2); the numbers, however, were not great enough for statistical analysis.

All patients with vitreous haemorrhage had detectable vitreous levels of PDGF (mean 77 $\mathrm{pg} / \mathrm{ml}$; range $35-106 \mathrm{pg} / \mathrm{ml}$ ). The causes of vitreous haemorrhage included horseshoe tear (five cases), disc neovascularisation (two cases, one secondary to branch retinal vein occlusion, the other secondary to proliferative diabetic retinopathy (PDR)) and one perforating eye injury (Table 2).

Four of the five patients with IOFBs, and no obvious vitreous haemorrhage, had detectable PDGF concentrations (mean $36.2 \mathrm{pg} / \mathrm{ml}$; range $30-40 \mathrm{pg} / \mathrm{ml}$ ) in their vitreous.

bFGF concentrations in the vitreous of 38 patients ranged from undetectable (in 26 samples) to $318.7 \mathrm{pg} / \mathrm{ml}$. All 12 vitreous samples with detectable bFGF had levels ranging between 5 and $318 \mathrm{pg} / \mathrm{ml}$ (mean $27.57 \mathrm{pg} / \mathrm{ml}$ ). The number of patients, divided according to their pathology, with detectable bFGF concentrations are summarised in Table 3.
Table 3 No of patients with detectable bFGF vitreous concentrations $(n=38)$

\begin{tabular}{llc}
\hline Vitreoretinal pathology & Detectable & Undetectable \\
\hline${ }^{\star} \mathrm{RD}+\mathrm{PVR}$ & 8 & 5 \\
${ }_{\mathrm{RD}}$ & 1 & 10 \\
Vitreous haemorrhage & 2 & 7 \\
IOFB & 1 & 4
\end{tabular}

* Statistical analysis using the Wilcoxon rank sum test indicates that bFGF concentrations are significantly higher in the vitreous of patients with RD + PVR than in patients with uncomplicated $\mathrm{RD}$ at the $\alpha<0.0001$ significance level.

A total of $61.5 \%(8 / 13)$ of patients with RD + PVR had detectable vitreous bFGF concentrations (mean $79.82 \mathrm{pg} / \mathrm{ml}$; range $0-318.7$ $\mathrm{pg} / \mathrm{ml}$ ), whereas only $1 / 11$ patients with $\mathrm{RD}$ and no PVR had detectable vitreous bFGF (7 $\mathrm{pg} / \mathrm{ml}$ ) (Table 2). The difference between these two groups was statistically significant when analysed using the Wilcoxon rank sum test, with an alpha $<0.001$ significance level. There did not appear to be any relation between the extent of PVR and the level of bFGF.

\section{Discussion}

The pathogenesis of PVR as described by Wiedemann and Weller, ${ }^{20}$ involves the migration of cells into the vitreous cavity, proliferation of these cells, synthesis of an extracellular matrix, and cellular contraction of this matrix. These tractional forces lead to RDs which are difficult to treat and have a poor visual prognosis. Cytokines which are known to stimulate this activity include TGF- $\beta,{ }^{21-25} \mathrm{PDGF}^{26-28}$ and some members of the endothelin family. ${ }^{29}$

bFGF, an angiogenic factor, has been shown to have an important role in the development of PDR, ${ }^{17}$ and by inference may have an important role in PVR.

The RPE plays a major role in wound repair and PVR, ${ }^{29}$ it forms a stable monolayer of cells which only proliferate during wound repair. Campochiaro et $a l^{12}$ have demonstrated that a PDGF autocrine loop is involved in RPE cell growth in serum free medium. This group has located PDGF in ganglion cells, retinal blood vessels, and in the RPE, but only when participating in wound repair, either adjacent to laser burns or underlying RD. They also found that PDGF and PDGF receptors are expressed in the RPE cells in epiretinal membranes removed during vitreous surgery. These findings are supported by those of Robbins et al. ${ }^{30} \mathrm{Nei}-$ ther group has studied levels of PDGF or bFGF in clinical vitreous samples.

Our study examined PDGF and bFGF concentrations in the vitreous of patients undergoing PPV, and has shown that both are elevated in eyes with RD and PVR but not in eyes with RD without PVR. The difference between these two groups is highly significant with an $\alpha$ $<0.001$ significance level. Our data support and expands Campochiaro et al's in vitro evidence that PDGF is a major player in the pathogenesis of PVR.

To make a distinction between eyes with RD without PVR and eyes with grade A PVR might be considered ambiguous, as it may be true that all eyes with RD have dispersion of RPE 
cells within the vitreous cavity; hence, all patients with RD could be considered to have grade A PVR. In this study all patients were carefully examined with a slit lamp, 90 dioptre, and 20 dioptre lenses and classified as having grade A PVR if obvious pigment clumping was present within the vitreous cavity. Those individuals with no visible pigment clumping in the vitreous were considered to have no PVR. We felt that there was a definite clinical distinction between these two groups of patients.

PDGF in eyes with grade A PVR tended to be higher than in eyes with grade C PVR. This suggests that PDGF may play a main role in the earlier stages of PVR. Our numbers were not great enough to be statistically significant, therefore no definite conclusion can be drawn from this observation.

bFGF levels, though raised in the vitreous of patients with PVR, could not be correlated with the degree of PVR; reasons for this include small patient numbers and the fact that the proliferative activity reflected by bFGF levels may have become quiescent despite the clinical stage of PVR. It would be interesting to investigate the possible existence of a relation between the severity of PVR and both PDGF and bFGF levels in a larger study, because if such a link existed then, possibly, routine assay of vitreous samples taken at the onset of surgery could be used to determine whether patients would benefit from intravitreal PDGF/ $\mathrm{bFGF}$ antibodies in order to minimise the risk of PVR. However, it has not yet come to the stage where such exciting immunotherapy is available, and no clinical trials have been published, but the potential exists.

Three cadaveric specimens were retrieved within 6 hours of death and examined for the presence of PDGF and bFGF. No detectable levels were found, which suggests that bFGF and PDGF are not found in normal vitreous. However, we cannot rule out that this may be a result of instability of PDGF and bFGF. We used vitreous samples from patients undergoing PPV for removal of IOFB as controls. These samples cannot be considered as true "normal" controls as breakdown of the bloodretinal barrier at the perforation site plus or minus vitreous haemorrhage would have allowed leakage of cytokine material into the vitreous cavity. Hanneken et al ${ }^{31}$ have demonstrated the presence of FGF binding proteins in the vitreous, and have suggested that these naturally occurring proteins may sequester free FGF in the vitreous cavity, and modulate the biological activity of FGF in vitreoretinal disease. To date no studies have included vitreous of healthy human eyes to determine if any and which particular cytokines are present under normal circumstances. Sivalingam et $a l{ }^{17}$ have examined human vitreous specimens for the presence of $b F G F$ and implicated its potential in the pathogenesis of PDR. Baudouin et $a l^{32}$ have looked at acidic fibroblastic growth factor basic (aFGF) in the vitreous of patients with PVR and found it to be present in $100 \%$ of cases. No data have been published regarding the presence of $\mathrm{bFGF}$ or
PDGF in clinical vitreous specimens of patients with PVR.

This study is an attempt to confirm Campochiaro et al's experimental findings with clinical material, and from our results we can observe that both PDGF and bFGF concentrations are significantly elevated in the vitreous of patients with RD and PVR when compared with patients with straightforward RD uncomplicated by PVR. Our findings suggest that both of these cytokines may play a role in the pathogenesis of PVR.

Lorraine Cassidy gratefully acknowledges the Research Department of the Royal Victoria Eye \& Ear Hospital, Dublin for ment of the Roya

Celine Shaw acknowledges a summer student grant from the Health Research Board of Ireland.

1 Ryan S J. The pathophysiology of proliferative vitreoretinopathy and its management. Am f Ophthalmol 1985; 100:188-93.

2 Cowley M, Conway BP, Campochiaro PA, Kaiser D, Gaskin H. Clinical risk factors for proliferative vitreoretinopathy. Arch Ophthalmol 1989;107:1147-51.

3 Campochiaro PA, Sugg R, Grotendorst G, Hjelmeland LM. Retinal epithelial cells produce PDGF-like proteins and secrete them into their media. Exp Eye Res 1989;49:21727.

4 Leschey $\mathrm{KH}$, Hackett SF, Singer JH, Campochiaro PA. Growth factor responsiveness of human retinal pigment Yeo JH, Sadeghi J, Campochiaro PA, Green WR, Glaser BM. Intravitreous fibronectin and platelet derived growth factor. New model for traction retinal detachment. Arch Ophthalmol 1986;104:417-21.

6 Narayanan AS, Page RC. Biosynthesis and regulation of type 5 collagen in diploid human fibroblasts. $\mathcal{f}$ Biol Chem 983:258:11694-9.

7 de Juan E, Dickson JS, Hjelmeland L. Serum is chemotactic for retinal derived glial cells. Arch Ophthalmol 1988;16: 986-90.

8 Harvey AK, Roberge F, Hjelmeland LM. Chemotaxis of rat retinal glia to growth factors found in repairing wounds. Invest Ophthalmol Vis Sci 1987;28:1092-9.

9 Gullberg D, Tingstrom A, Thuresson A, Olsson L, Terracio L, Borg TK, et al. Beta-1 integrin-mediated collagen gel contraction is stimulated by PDGF. Exp Cell Res 1990;186: 264-72.

10 Campochiaro PA, Glaser BM. Platelet-derived growth factor is chemotactic for human retinal pigment epithelial cells. Arch Ophthalmol 1985;103:576-9.

11 Seppa H, Grotendorst G, Seppa S, Schiffen E, Martin GR. Platelet derived growth factor is chemotactic for fibroblasts. F Cell Biol 1982;92:584-8.

12 Campochiaro PA, Hackett SF, Vinores SA, Freund J, Csaky C, LaRochelle W. Platelet derived growth factor is an autoC, LaRochelle W. Platelet derived growth factor is an auto-
crine growth stimulator in retinal pigment epithelial cells. $\mathcal{F}$ crine growth stimulator in retr

13 Barnes D, Sato G. Methods for growth of cultured cells in serum free medium. Anal Biochem 1980;102:155-70.

14 Courty J, Chevallier B, Moenner M, Loret C, Lagente O, Bohlen P, et al. Evidence for FGF-like growth factor in adult bovine retina: analogies with EDGF 1. Biochem Biophys Res Commun 1986;136:102-8.

15 Quarto N, Finger FP, Rifkin DB. The NH2-terminal extension of high molecular weight bFGF is a nuclear targeting signal. 7 Cell Physiol 1991;147:311-8.

16 Bugler B, Amalric F, Prats H. Alternative initiation of translation determines cytoplasmic or nuclear localisation of basic fibroblast growth factor. Mol Cell Biol 1991;11: 573-7.

17 Sivalingam A, Kenney J, Brown GC, Benson WE, Donoso L. Basic fibroblast growth factor levels in the vitreous of patients with proliferative diabetic retinopathy. Arch patients with proliferative
Ophthalmol 1990;108:869-72

18 Gospodarowicz D, Massoglia S, Cheng J, Lui GM, Bohlen P. Isolation of pituitary fibroblast growth factor by fast protein liquid chromatography: partial chemical and biological tein liquid chromatography: partial chemical and
characterisation. $\mathcal{F}$ Cell Physiol $1985 ; 122: 323-32$.

19 The Retina Society Terminology Committee. The classification of retinal detachment with proliferative vitreoretinopathy. Ophthalmology 1983;90:121-5.

20 Wiedemann P, Weller M. The pathophysiology of proliferative vitreoretinopathy. Acta Ophthalmol (Suppl) 1988;189: 3-15.

21 Raymond MC, Thompson JT. RPE-mediated collagen gel contraction: inhibition by colchicine and stimulation by TGF-alpha. Invest Ophthalmol Vis Sci 1990;31:1070-86.

22 Finesmith T, Broadley K, Davidson J. Fibroblasts from wounds of different stages of repair vary in their ability to contract a collagen gel in response to growth factors. $f$ Cell Physiol 1990;114:99-107.

23 Montesano R, Orci L. Transforming growth factor beta stimulates collagen-matrix contraction by fibroblasts: 1988;85:4894-7. 
24 Ura H, Obara T, Yokota K, Shibata Y, Okamura K, Namiki $M$. Effects of transforming growth factor-beta released from gastric carcinoma cells on the contraction of collagen-matrix gels containing fibroblasts. Cancer Res 1991;51:3550-4.

25 Pena R, Jerdan J, Glaser B. Effects of TGF-B and TGF-B neutralising antibodies on fibroblast-induced collagen gel contraction: implications for proliferative vitreoretinopathy. Invest Ophthalmol Vis Sci 1994;35:2804-8.

26 Gullberg D, Tingstrom A, Thuresson AC, Olsson L, Terracio L, Borg TK, et al. Beta-1 integrin-mediated collagen gel contraction is stimulated by PDGF. Exp Cell Res 1990;186: $273-4$.

27 Anderson SN, Ruben Z, Fuller G. Cell-mediated contraction of collagen lattices in serum free medium: effect of serum and nonserum factors. In Vitro Cell Dev Biol 1990;26:61-6.
28 Clark RA, Folkvord JM, Hart CE, Murray MJ, McPherson JM. Platelet isoforms of platelet derived growth factor stimulate fibroblasts to con

29 Guidry C, Hook M. Endothelins produced by endothelial cells promote collagen gel contraction by fibroblasts. $\mathcal{F}$ Cell Biol 1991;115:873-80.

30 Robbins SG, Mixon RN, Wilson DJ, Hart CE, Robertson JA, Westra I, et al. Platelet derived growth factor ligands and receptors immunolocalised in proliferative retinal diseases. Invest Ophthalmol Vis Sci 1994;35:3649-63.

31 Hanneken A, Baird A. Soluble forms of the high-affinity fibroblast growth factor receptor in human vitreous fluid. Invest Ophthalmol Vis Sci 1995;36:1192-6.

32 Baudouin C, Fredj-Reygrobellet D, Brignole F, Negre F, Lapalus P Gastaud P. Growth factors in vitreous and subretinal fluid cells from patients with proliferative vitreoretinopathy. Ophthalmic Res 1993;25:52-9. 